\title{
Sulphonation of Expanded Polystyrene Waste Under Microwave Irradiation
}

\author{
Wiesław W. Sułkowski, ${ }^{1 *}$ Agnieszka Wolińska, ${ }^{1}$ Anna Sułkowska, ${ }^{2}$ Krzysztof \\ Nowak, ${ }^{1}$ Dariusz Bogdal ${ }^{3}$
}

${ }^{1 *}$ Department of Environmental Chemistry and Technology, Institute of Chemistry, University of Silesia, Szkolna 9, 40-006 Katowice, Poland, tel/fax: ++ 4832 3591371; e-mail: wieslaw.sulkowski@us.edu.pl

${ }^{2}$ Department of Physical Pharmacy, Medical University of Silesia, Jagiellońska 4, Sosnowiec, Poland

${ }^{3}$ Chair of Chemistry and Technology of Polymers, Cracow University of Technology, Warszawska 24, 31-155 Kraków, Poland

(Received: 25 July, 2007; published: 8 January, 2008)

\begin{abstract}
Chemical modification of polymeric materials is one way of polymer waste management. In our study, expanded polystyrene waste (EPS), used as the reference material, was converted into polymeric flocculants by the sulphonation reaction. Thus, poly(styrenesulphonate) acids (EPSS) were obtained from EPS during the sulphonation process with sulphuric acid as the sulphonation agent and $\mathrm{Ag}_{2} \mathrm{SO}_{4}$ as the catalyst under both conventional heating and microwave conditions. At the termination of the process the products were precipitated in the form of sodium salts (NaEPSS) in the reaction with $\mathrm{Na}_{2} \mathrm{CO}_{3}$ and their characteristics were given. The influence of temperature and time of reaction on the properties of EPSS and NaEPSS was studied and compared with conventional and microwave conditions. The results showed that the sulphonation process performed under microwave irradiation allowed us to receive products with properties similar to the ones obtained under conventional conditions but the reaction time was substantially reduced from 1 and $1 / 2$ hour to $15 \mathrm{~min}$.

Keywords: Flocculation; Microwave Irradiation; Polystyrene; Polyelectrolytes; Sulphonation; Sulphonic derivatives; Waste
\end{abstract}

\section{Introduction}

Application of microwave irradiation in chemistry is an attractive technique since due to it a number of chemical processes can be carried out with a substantial reduction in the reaction time in comparison to conventional processes [1]. Recently, microwave technology applied to polymer processing, and particularly to the polymerization process has become a subject of a great deal of scientific and industrial research. Microwave technology has been widely accepted as a popular unconventional technology in polymer chemistry and also as an alternative to, and often improvement on, conventional heating [2-6].

Microwave irradiation has been applied for chemical modification of a number of natural polymers [7-14]. Hence the idea of applying microwave irradiation to reactions on polymer matrixes in which polymer solubility and, in consequence, reactions in dense medium/phase are the main obstacles for high degree of substitutions under conventional conditions. 
Sulphonation reactions of aromatic compounds under microwave irradiation as well as their kinetics have been the subject of several investigations $[15,16]$ whereas the process of sulphonation of polymers, and, in particular of polystyrene, under microwave conditions has not been described in literature so far. The latter case is important since it allows us to convert polystyrene waste (EPS) into poly(styrenesulphonate) acids (EPSS), which can be used as a polyelectrolyte to accelerate flocculation processes [17].

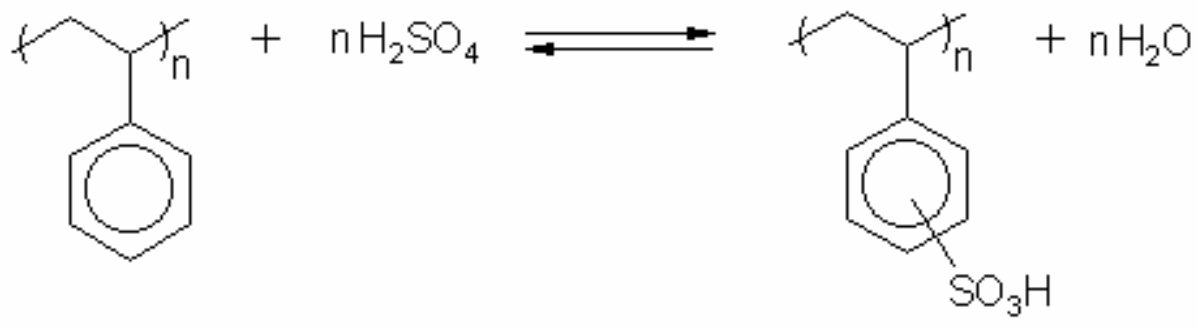

Flocculation is an essential stage in many solid/liquid separation processes, especially in wastewater treatment or sludge conditioning when the solid particles are too small to be effectively removed. Sulphonation of PS matrices can be performed by various methods [17-24]. Hence microwave assisted method can be a new alternative for the conventional process of modification of polystyrene waste as well as polymer waste management.

In our study, the properties of the sulphonated expanded polystyrene (EPSS) waste obtained by the conventional method and under microwave heating were compared. The products were precipitated in the form of sodium salt (NaEPSS) in the reaction with $\mathrm{Na}_{2} \mathrm{CO}_{3}$ and their characteristics were given. The influence of temperature and time of reaction on the properties of EPSS and NaEPSS was also studied.

\section{Results and Discussion}

The derivatives obtained under conventional heating conditions (NaEPSS) were obtained with $100 \%$ yield and were soluble in water. The values of molecular weight $\mathrm{M}_{\eta}$ were of the range from 368000 to 570000 . For example, NaEPSS obtained in the reaction conducted for $11 / 2 \mathrm{~h}$ at $80-90^{\circ} \mathrm{C}$ have the maximum value of $M_{\eta} 515000$. The value of $n$.sulph for this product was equal to 0.96 . NaEPSS with the maximum values of n.sulph $M_{\eta}$ were obtained when the sulphonation process was carried out for 1 or $11 / 2 \mathrm{~h}$, respectively. With increase of the reaction time above $1 \frac{1 / 2}{h}$, the decrease of the n.sulph and $M_{\eta}$ values was observed. It seems probable that some processes of desulphonation and/or degradation of the polymer occurred in the reaction system when the reaction time exceeded 1.50 hour [11] (Table 1).

For NaEPSS obtained at $100-110^{\circ} \mathrm{C}$, the values of $\mathrm{n}$.sulph rise with the increase of the reaction time up to $11 / 2$ or $2 \mathrm{~h}$ and yield maximum value. The $\mathrm{n}$.sulph decreases with the increase of the reaction time up to 12.00 hours. The decrease of the n.sulph value points toward the lack of cross-linking between the macromolecules since the products are still soluble in water. The decrease of the values of n.sulph suggest that the sulphonic groups are removed from the modified molecules and probably give rise to the intramolecular bonds in products with postulated sulphone-type crosslink structures [17].

On comparison of the results of the experiments under microwave and conventional conditions, it is worth stressing that microwave irradiation allows us to obtain more 
homogeneous products. It seems that microwave irradiation favours the course of the reaction without the cross-linking of the polymer. This can be the result of the reduced time scale of the process to $15-30 \mathrm{~min}$. from 1 and $1 \frac{1}{2} \mathrm{~h}$ in comparison with conventional heating. Thus, one of the arguments for the application of microwave irradiation during the sulphonation process of expanded polystyrene waste (EPS) is to prevent the occurrence of undesirable reactions such as cross-linking or degradation of polymer chains.

Tab. 1. Number of sulphonic groups per one monomer unit (n.sulph) and molecular weight $\left(\mathrm{M}_{\eta}\right)$ of NaEPSS obtained during sulphonation processes of EPS on thermal heating at two temperature ranges. The experiments were performed for the molar ratio EPS:acid equal to $1: 5$.

\begin{tabular}{ccccccc}
\hline Reaction & \multicolumn{3}{c}{ NaEPSS 80-90 } & \multicolumn{3}{c}{ NaEPSS $100-110^{\circ} \mathrm{C}$} \\
\cline { 2 - 6 } time & n.sulph & $\mathrm{M}_{\eta}$ & $\mathrm{M}_{\text {cal }}$ & n.sulph & $\mathrm{M}_{\eta}$ & $\mathrm{M}_{\text {cal }}$ \\
$\mathrm{h}$ & & & & & & \\
\hline 0.25 & 0.86 & 427000 & 426000 & 0.87 & 480000 & 424000 \\
0.50 & 0.89 & 430000 & 451000 & 0.98 & 491000 & 431000 \\
0.75 & 0.95 & 450000 & 460000 & 1.02 & 479000 & 444000 \\
1.00 & 0.97 & 470000 & 467000 & 1.05 & 510000 & 449000 \\
1.50 & 0.96 & 515000 & 480000 & 1.11 & 508000 & 447000 \\
2.00 & 0.96 & 495000 & 476000 & 1.09 & 520000 & 447000 \\
3.00 & 0.85 & 475000 & 473000 & 1.08 & 550000 & 422000 \\
4.00 & 0.85 & 452000 & 449000 & 0.97 & 530000 & 422000 \\
5.00 & 0.82 & 420000 & 444000 & 0.95 & 570000 & 415000 \\
8.00 & 0.85 & 370000 & 422000 & 0.85 & 560000 & 422000 \\
12.00 & 0.57 & 368000 & 354000 & 0.55 & 570000 & 359000 \\
\hline
\end{tabular}

Further study of the effect of the reaction temperature and time, of the molar ratio of EPS and of sulphuric acid showed that it is possible to obtain sodium salt of the poly(styrenesulphonic acid) (NaEPSS ${ }_{M W}$ ) with suitable molecular weight and n.sulph even within 10 to 15 min (Table 2). The maximum values of molecular weight $M_{\eta}$ for the products obtained under microwave irradiation was 565000 with n.sulph value of 0.91 .

To show the influence of the amount of the sulphuric acid on the sulphonation of EPS, experiments with a lower ratio of sulphuric acid to EPS than 5 were performed (Table 2). It was found that sulphonation of EPS with the use of a smaller excess of $\mathrm{H}_{2} \mathrm{SO}_{4}$ yielded a product with lower $\mathrm{M}_{\eta}$, despite the fact that the period of the synthesis $(15 \mathrm{~min})$ and temperature $\left(80-90^{\circ} \mathrm{C}\right)$ were of the same range in each case. The same effect was observed, for the reaction carried out for a period shorter than 10-15 min. However the process of sulphonation conducted at $80-90{ }^{\circ} \mathrm{C}$, it seems that $5 \mathrm{~min}$ is probably too short a time for the reaction to be completed.

The reaction under microwave irradiation at $100-110{ }^{\circ} \mathrm{C}$ for $15 \mathrm{~min}$. yielded a product with lower molecular weight and higher values of n.sulph in comparison with the reaction at $80-90{ }^{\circ} \mathrm{C}$. For example, $M_{\eta}$ increased from 470000 to 565000 for 100$110^{\circ} \mathrm{C}$ and $80-90{ }^{\circ} \mathrm{C}$, respectively, while n.sulph values decreased from 1.16 to 0.91 . On performing the process for EPS at $100-110^{\circ} \mathrm{C}$ for $30 \mathrm{~min}$. it occurred, that for the obtained product the value of $M_{\eta}$ was one of the lowest and equalled 289000 while 
the value of $n$.sulph was one of the highest and equalled 1.56. This was probably due to the fact that the reaction time lasted too long at the high temperature range (Table 2). The results of the experiments showed that during the sulphonation processes of EPS under microwave irradiation some undesirable processes may have occurred, affecting the structure of the obtained derivatives. The same effect was observed for products obtained under conventional conditions for a longer time of reaction.

Tab. 2. Number of sulphonic groups per one monomer unit (n.sulph) and molecular weights $\left(\mathrm{M}_{\eta}\right)$ of NaEPSS $\mathrm{MW}_{\mathrm{W}}$ obtained during sulphonation processes of EPS at two temperature ranges under microwave irradiation.

\begin{tabular}{cccccc}
\hline $\begin{array}{c}\text { The molar } \\
\text { ratio } \\
\text { EPS : acid }\end{array}$ & $\begin{array}{c}\text { Temp } \\
{ }^{\circ} \mathrm{C}\end{array}$ & $\begin{array}{c}\text { Time } \\
\text { min }\end{array}$ & n.sulph & $\mathrm{M}_{\eta}$ & $\mathrm{M}_{\text {cal }}$ \\
\hline $1: 5$ & $100-110$ & 30 & 1.56 & 289000 & 582000 \\
$1: 5$ & $100-110$ & 15 & 1.16 & 470000 & 492000 \\
$1: 5$ & $100-110$ & 10 & 0.87 & 381000 & 426000 \\
$1: 5$ & $80-90$ & 15 & 0.91 & 565000 & 435000 \\
$1: 4$ & $80-90$ & 15 & 0.85 & 523000 & 422000 \\
$1: 3$ & $80-90$ & 15 & 0.55 & 449000 & 354000 \\
$1: 2$ & $80-90$ & 15 & 0.49 & 381000 & 341000 \\
\hline
\end{tabular}

Preliminary results of the flocculation study showed that the NaEPSS ${ }_{\mathrm{MW}}$ was almost as effective as the NaEPSS, causing the decrease of turbidity of the waste discharge model system to $90 \%$ of the initial turbidity of $\mathrm{Fe}(\mathrm{OH})_{3}$, which will be reported completely in our next paper.

\section{Conclusions}

The sulphonation process of expanded polystyrene waste (EPS) under conventional and microwave conditions with the use of sulphuric acid (VI) allowed us to obtain NaEPSS polyelectrolytes. The sulphonation carried out under microwave irradiation resulted in the reduction of the temperature and time of reaction in comparison with conventional heating conditions. Moreover, the molecular weights $M_{\eta}$ and n.sulph for the products obtained under microwave conditions were compared with $M_{\eta}$ and n.sulph obtained for the polyelectrolytes under conventional conditions. As a result of sulphonation of EPS at $80-90{ }^{\circ} \mathrm{C}$ for $15 \mathrm{~min}$. under microwave irradiation the obtained polystyrene derivatives had the $M_{\eta}$ value equal to 565000 and $n$. sulph was 0.91 . Under conventional conditions, the maximum value of $n$. sulph equalled 1.11 and of $M_{\eta}$ was 508000 after 1 and $1 / 2 h$.

As it was stated in the experimental section, the suspensions of PS in sulphuric acid are highly viscous and they become homogenous after a few minutes of either microwave or conventional heating. However it has been proved that microwave heating is particularly beneficial for the reactions in highly viscous media in which the heat transfer under conventional treatment conditions is difficult [1]. Microwave 
heating is a means of volumetric heating of the material and gives rise to very rapid energy transfer into the material being heated. It also causes more extensive heating inside the material than in the outer layers of the material, especially in dense media. In our opinion, to explain the acceleration of the sulphonation of PS under microwave irradiation, a more effective heating mechanism of a dense reaction mixture should be taken into account before considering the so-called non-thermal microwave effects. Moreover, the solutions of PS in sulphuric acid are good microwave absorbers that couple efficiently with microwaves and cause a rapid temperature increase under microwave irradiation.

\section{Experimental Part}

\section{Materials}

Expanded polystyrene wastes (EPS) of $M_{\eta E P S}=230000$ were dried and pulverised in a mill and fractions of the size $0.40-1.04 \mathrm{~mm}$ were separated and used in the reactions. Sulphuric acid, calcium carbonate, sodium carbonate, and silver sulphate produced by Chemical Company POCh in Gliwice Poland were applied without further purification.

\section{Techniques and Instruments}

The IR spectra for the NaEPSS and NaEPSS ${ }_{M W}$ derivatives were recorded on the Perkin-Elmer Spectrum One FTIR spectrometer. Samples were prepared in the form of $\mathrm{KBr}$ discs. The content of sulphur and carbon in products of PS sulphonation was determined using Perkin Elmer $\mathrm{CHNS/O}$ elementary analyser. The contents of sulphur and carbon were then used for calculations of the number of sulphonic groups per one monomer unit (n.sulph). The quotient of sulphur and carbon contents was linearly dependent on n.sulph for the theoretical structures of NaEPSS [17]. The data obtained from the elementary analysis were taken to calculate the theoretical molecular weight values $\mathrm{M}_{\text {cal }}$ in the manner described previously [17].

The NaEPSS and NaEPSS $\mathrm{MW}_{\mathrm{W}}$ samples were characterised by determining their intrinsic viscosities $[\eta]$ in $0.5 \mathrm{M} \mathrm{NaCl}$ solution at $25{ }^{\circ} \mathrm{C}$. The measurements were carried out with an Ubbelohde type of viscometer. Parameters $K=1.86 \times 10^{-4}$ and $a=0.64$ (from Mark-Houwink equation), determined by light-scattering measurements for the same conditions, were used to obtain the molecular weight of the samples [22].

\section{Sulphonation Under Conventional Conditions}

Pulverised polystyrene samples (EPS) were suspended in sulphuric acid (5 times its weight) and silver sulphate (1\% of its weight) was added as a catalyst. The amount of $\mathrm{Ag}_{2} \mathrm{SO}_{4}$ was dissolved in $\mathrm{H}_{2} \mathrm{SO}_{4}(95-97 \%)$ in a glass flask equipped with mechanical agitator, vertical condenser and thermometer. Then polystyrene (EPS) was added at $80{ }^{\circ} \mathrm{C}$, and the reaction mixture was stirred at $80-90{ }^{\circ} \mathrm{C}$. To find the dependence between the sulphonation conditions and the properties of the final product, we varied the temperature and time of reaction. The sulphonation was carried out from $15 \mathrm{~min}$. to $12 \mathrm{~h}$. However, within a few minutes the reaction mixture became highly viscous and seemingly homogeneous. The product was separated by filtration, dissolved in deionised water and then precipitated in the form of sodium salt in the reaction with $\mathrm{Na}_{2} \mathrm{CO}_{3}$. The same experiments were performed at the temperature 
range from $100-110{ }^{\circ} \mathrm{C}$. As a result sodium salts of poly(styrenesulphonic acid) (NaEPSS) were obtained.

\section{Sulphonation Process Under Microwave Irradiation}

Preparation of poly(styrenesulphonate) sodium salt (NaEPSS $\mathrm{MW}_{\text {) }}$ under microwave irradiation was similar to the preparation of poly(styrenesulphonic acid) (NaEPSS) under conventional conditions. Similar amounts of reagents and of the catalyst were taken for the same set of reaction conditions.

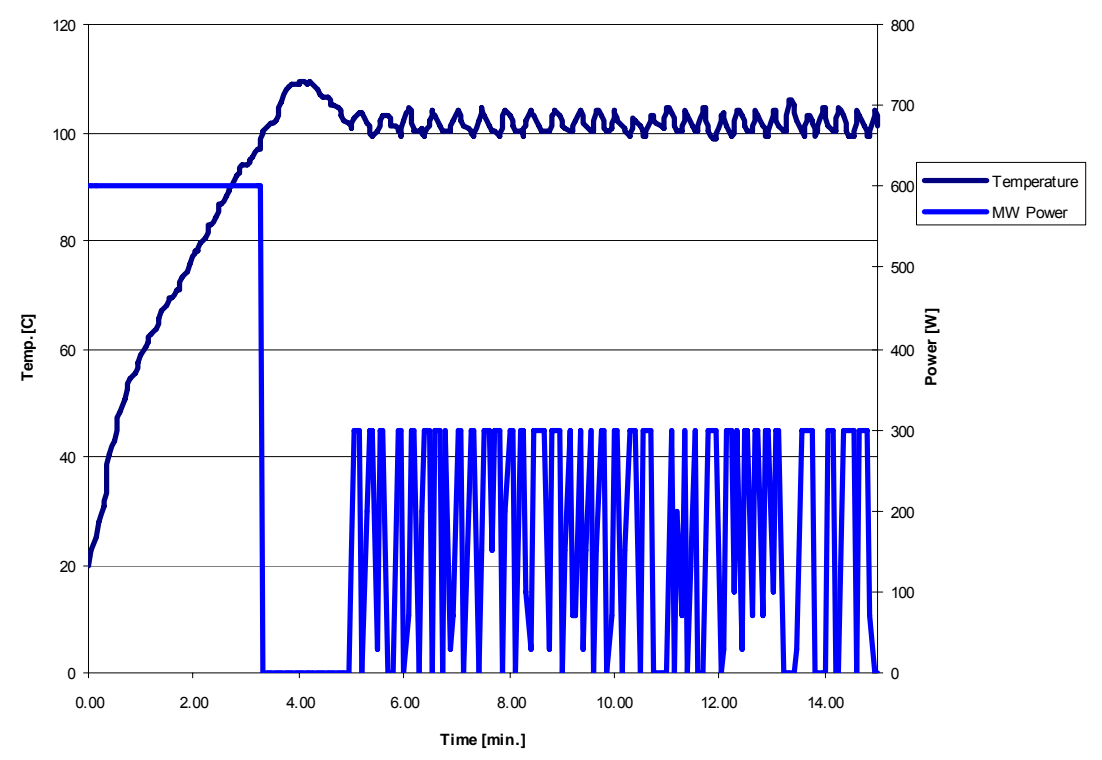

Fig.1. Temperature and power profiles for the sulphonation of PS under microwave irradiation at $100-110^{\circ} \mathrm{C}$.

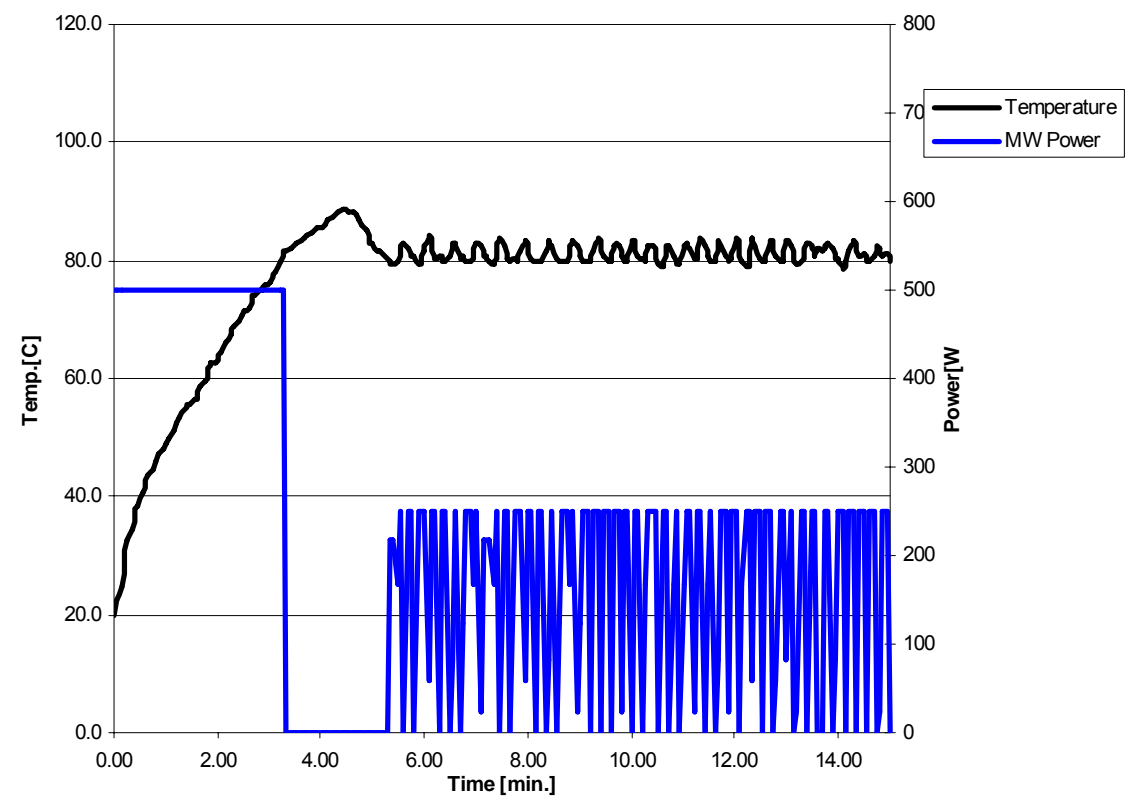

Fig. 2. Temperature and power profiles for the sulphonation of PS under microwave irradiation at $80-90{ }^{\circ} \mathrm{C}$. 
The reactions were carried out at $80-90{ }^{\circ} \mathrm{C}$ and $100-110{ }^{\circ} \mathrm{C}$ in the multimode microwave reactor Plazmatronika $(600 \mathrm{~W})$ equipped with magnetic stirrer, temperature and power controls by means of a pyrometer back coupled with a microwave source (i.e. magnetron). Prior to the processes, the pyrometer was calibrated with a fibre-optic sensor (Neooptix) under microwave irradiation (Fig.s 1 and 2).

To find the dependence between the sulphonation conditions and the properties of the final product, temperature, time of reaction and amount of sulphuric acid were varied. The sulphonation was carried out from 5 to $30 \mathrm{~min}$. The product was separated by filtration, dissolved in deionised water and then precipitated in the form of sodium salt in the reaction with $\mathrm{Na}_{2} \mathrm{CO}_{3}$. As a result sodium salts of poly(styrenesulphonic acid) (NaEPSS ${ }_{M W}$ ) were obtained.

\section{References}

[1] Loupy, A. Ed., "Microwaves in Organic Synthesis", Wiley-VCH, Weinheim 2006.

[2] Parodi, F. "Physics and Chemistry of Microwave Processing", in: Comprehensive Polymer Science, $2^{\text {nd }}$ Supplement, S.L. Aggarwal, E. Russo, Eds., Pergamon, Oxford 1996.

[3] Bogdal, D.; Penczek, P.; Pielichowski, J.; Prociak, A. Adv. Polym. Sci. 2003, 163, 193.

[4] Wiesbrock, F.; Hoogenboom, R.; Schubert, U.S. Macromol. Rapid. Commun. 2004, 25, 1739.

[5] Bogdal, D.; Matras, K. "Polymer Chemistry under Action of Microwave Irradiation", in: Microwaves in Organic Synthesis, A. Loupy, Ed., Wiley-VCH, Weinheim, 2006.

[6] Bogdal, D.; Prociak, A. "Microwave-Enhanced Polymer Chemistry and Technology", Blackwell Publishing Profesionals, 2007.

[7] Gourson, C.; Benhaddou, R.; Granet, R.; Krausz, P.; Saulnier, L.; Thibault, J. F. C. R. Acad. Sci. Paris 1999, 2, 75.

[8] Satge, C.; Verneuil, B.; Branland, P.; Granet, R.; Krausz, P.; Rozier, J.; Petit, C. Carbohydr. Polym. 2002, 49, 373.

[9] Gospodinova, N.; Grelard, A.; Jeannin, M.; Chitanu, G. C.; Carpov, A.; Thiery, V.; Besson, T. Green Chem. 2002, 4, 220.

[10] Muzimbaranda, C.; Tomasik, P. Starch, 1994, 46, 469.

[11] Shogren, R. L.; Biswas, A. Carbohydr. Polym. 2006, 64, 16.

[12] Biswas, A.; Shogren, R.L.; Kim, S.; Willet, J. L. Carbohydr. Polym. 2006,64, 484.

[13] Siemion, P.; Kapusniak, J.; Koziol, J. Carbohydr. Polym. 2005, 62, 182.

[14] Koroskenyi, B.; McCarthy, S.P. J. Polym. Environm. 2002, 10, 93.

[15] Abramovitch, R. A.; Abramovitch, D.; Iyanar, K.; Tamreselvy, K. Tetrahedron Lett., 1991, 32, 5251.

[16] Stuerga, D.; Gonon, K.; Lallemant, M. Tetrahedron, 1993, 49, 6229.

[17] Sułkowski, W. W.; Wolińska, A.; Szołtysik, B.; Bajdur, W. M.; Sułkowska, A. Polym. Degrad. Stabil. 2005, 90, 272.

[18] Turbak, A. Ind. Eng. Chem. 1962, 1, 275.

[19] US Patent 3,072,618, 1963.

[20] Goldstein, S.; Schmuckler, G. Ion Exch. Membranes 1972, 1, 63.

[21] Roth, H. Ind. Eng. Chem. 1954, 46, 2435.

[22] Neiho f, R. Coll. Inter. Sci. 1954, 58, 916.

[23] Regas, F. Polymer 1984, 25, 249.

[24] Thodoropoulous, A.; Tsakalos, V.; Valkanas, G. Polymer 1993, 34, 3905. 